\title{
BMJ Open Long-term benzodiazepine use in patients taking antidepressants in a public health setting in Brazil: a cross- sectional study
}

\author{
Izabela Fulone, Marcus Tolentino Silva, Luciane Cruz Lopes
}

To cite: Fulone I, Silva MT, Lopes LC. Long-term benzodiazepine use in patients taking antidepressants in a public health setting in Brazil: a cross-sectional study. BMJ Open 2018;8:e018956. doi:10.1136/ bmjopen-2017-018956

- Prepublication history for this paper is available online. To view these files, please visit the journal online (http://dx.doi. org/10.1136/bmjopen-2017018956).

Received 5 August 2017 Revised 11 January 2018 Accepted 18 January 2018
Check for updates

Pharmaceutical Sciences Master Course, University of Sorocaba, UNISO, Sorocaba, São Paulo, Brazil

Correspondence to Dr Luciane Cruz Lopes; luslopes@terra.com.br

\section{ABSTRACT}

Objective The aims of the study were to investigate the prevalence of long-term use of benzodiazepines in patients taking antidepressants and to identify the risk factors associated with the prolonged use of benzodiazepines. Design Cross-sectional study.

Setting Public health system in Brazil.

Participants Outpatients using antidepressants from January 2008 to December 2009 were included. The data were obtained from pharmacy databases and medical records. All individuals in the database were included in the study and were classified into two categories: (1) patients who had not used benzodiazepines combined with antidepressants or had combined the use of antidepressants with benzodiazepines for a short period (up to 4 weeks), and (2) those who used antidepressants plus benzodiazepines for a longer period (more than 4 weeks).

Main outcome measure The outcome measure is prolonged use of benzodiazepines (more than 4 weeks). We conducted a multivariate analysis to identify the factors associated with prolonged use of benzodiazepines. Results Forty per cent of the 870 patients evaluated had prolonged use of benzodiazepines (more than 4 weeks). The risk factors associated with prolonged use were age above 35 years (prevalence ratio (PR): $2.18,95 \% \mathrm{Cl} 1.55$ to $3.06, \mathrm{P}<0.001$ ), female sex (PR: $1.47,95 \% \mathrm{Cl} 1.07$ to 2.02 , $\mathrm{P}=0.019$ ), diagnosis at least 3 years prior (PR: $2.1,95 \% \mathrm{Cl}$ 1.6 to $2.8, P<0.001$ ), use of selective serotonin reuptake inhibitor antidepressants (PR: 1.7, 95\% Cl 1.3 to 2.2, $\mathrm{P}<0.001)$ and having a prescription from a psychiatrist (PR: $6.5,95 \% \mathrm{Cl} 3.2$ to $13.2, \mathrm{P}<0.001)$.

Conclusions Prolonged use of benzodiazepines occurs more frequently in women, adults diagnosed several years earlier, users of selective serotonin reuptake inhibitor antidepressants and those who received a prescription from a psychiatrist. Education of clinicians, especially with regard to these populations, may decrease the overuse and misuse of benzodiazepines.

\section{INTRODUCTION}

Benzodiazepines and antidepressants are the most frequently prescribed psychotropic medications and are used by $5 \%-10 \%$ of the community in high-income countries. ${ }^{12}$ Most of the data suggesting misuse of these drugs
Strengths and limitations of this study

This study presents the first detailed data on the prolonged use of benzodiazepines plus antidepressants in Brazilian patients in the public health system.

- Although this study included a non-probabilistic sample, it refers to a context with strong presence in the public health services, where all records were collected. The public health system assists $75 \%$ of the population in the Brazilian cities.

- Our findings relate to antidepressants and benzodiazepines prescribed and accessed from the public pharmacy and may not correspond to use or adherence.

come from high-income countries, whereas low-income and middle-income countries have witnessed a rise in the diagnosis of mental disorders and in the use of psychotropic medication. $^{34}$

In 1998, a study using data from the Brazilian health system showed that $19 \%$ of chronic diseases were neuropsychiatric disorders. ${ }^{3}$ São Paulo had the highest prevalence of depression when compared with cities in 18 other high-income, middle-income and low-income countries. ${ }^{5}$

On the other hand, a rather poor relationship between diagnoses and prescriptions has indeed been suggested, because psychotropic medication is also prescribed for a wider range of emotional problems in patients without a formal Diagnostic and Statistical Manual of Mental Disorders diagnosis. ${ }^{1}$ Therefore, the use of benzodiazepines extends far beyond the approved and clinically accepted off-label indications. $^{67}$

Benzodiazepines are commonly used for the treatment of anxiety and insomnia and are also used as adjunct therapies for schizophrenia and depression. ${ }^{7}$ Despite the lack of evidence supporting their use beyond short periods, benzodiazepines are often prescribed 
for much longer periods than recommended. ${ }^{8-10}$ This prolonged use is associated with the development of dependence, tolerance and adverse reactions, including cognitive impairment, dementia, falls and consequent fractures. ${ }^{11-13}$

Furthermore, combined prescriptions of antidepressants plus benzodiazepines are common in many parts of the world. ${ }^{14}$ A meta-analysis involving 10 randomised clinical trials showed that the combined use of antidepressants and benzodiazepines reduced the severity of depression symptoms by more than $50 \%$ and resulted in a lower dropout rate until the fourth week of treatment compared with treatment with antidepressants alone. Subsequently, these benefits disappeared. ${ }^{15}$

However, research conducted in the USA, Canada, Spain and China has shown that there have been failures to withdraw from benzodiazepines during antidepressant therapy, because most patients with depression continued to use long-term combined treatment with antidepressants and benzodiazepines. ${ }^{16-18}$

Recent research conducted in Brazil has shown that benzodiazepines are the psychotropic agents most often prescribed by physicians and are used for much longer periods than recommended by the guidelines. ${ }^{10}$ A lack of time to discuss and evaluate each case in the face of the great demand that exists in the public health system, the practice of repeating psychotropic prescriptions and sparse follow-up practices contribute considerably to the high rates of consumption and extended time of use of antidepressants and benzodiazepines in Brazil.

The healthcare system, physicians' erroneous indications and patient characteristics are associated with psychotropic prescription patterns. ${ }^{1}$ Findings consistently suggest that the following characteristics are strongly associated with the use of benzodiazepines and/ or antidepressants: being female, being 35 years of age or older, having lower education, being unemployed, having painful physical symptoms and seeking help for emotional problems. ${ }^{1} 101418$

In countries such as Brazil, which has a public health system of universal coverage, it is common to observe prescription repetition by the prescriber, bad practices involving the misuse of medicines, and a lack of databases to facilitate the analysis of patterns and behaviours of drug use, especially in rural areas where it is difficult to access information. ${ }^{19}$ For these reasons, it is important to understand these processes in Brazil to ensure that decision makers can change health policy.

The harms stemming from the long-term use of benzodiazepines are well recognised. Hence, guidelines limit their use to only a few weeks and provide advice on the need to follow effective discontinuation strategies. In spite of these guidelines, physicians continue prescribing these drugs, and the long-term use rates are still very high. ${ }^{720}$ The factors related to patients that may contribute to such misuse of benzodiazepines remain uncertain.

Our goals in the current study were to investigate the prevalence of the long-term use of benzodiazepines in patients taking antidepressants and to identify the risk factors associated with prolonged benzodiazepine use.

\section{METHODS}

\section{Design, setting and context}

This study had a cross-sectional design. The participants were all patients being treated with antidepressants and assisted by the public health service of the Brazilian city Porto Feliz. The study used the centralised database of the public pharmacy outlet for dispensing drugs under the special control of Porto Feliz, Brazil. The public health system has a list of antidepressants that can be prescribed by physicians to be dispensed by the public pharmacy. The following antidepressants are on the list: amitriptyline, clomipramine, imipramine, nortriptyline, citalopram, fluoxetine and sertraline.

Porto Feliz is approximately $120 \mathrm{~km}$ from São Paulo. Its population is approximately 51628 inhabitants, and nearly $16 \%$ live in rural areas. Its economy is based on agriculture (sugar cane and grapes), and it has a high Human Development Index (0.8) ${ }^{21}$ It has been estimated that $75 \%$ of its inhabitants are assisted by its public health service, which includes doctor visits, diagnostic procedures and access to medications.

\section{Sample selection}

First, the study identified all users of antidepressants in the pharmacy database regardless of age. Our first source of data was the pharmacy database. We took all the data from patients whose records indicated prescriptions of antidepressants from January 2008 to December 2009. All individuals in the database were included in the study. From this group of patients, we identified those who had used benzodiazepines alone and those who had used them in combination with antidepressants. The patients were classified into two categories: (1) patients who had not used benzodiazepines combined with antidepressants or had experienced the combined use of antidepressants plus benzodiazepines for a short period (up to 4weeks), and (2) those who used antidepressants plus benzodiazepines for a longer period (more than 4 weeks). The threshold was based on the Cochrane systematic review ${ }^{15}$ and other recent studies. ${ }^{22} 23$ In addition to the pharmacy database, we used the original medical records to obtain more information about ICD-10 (International Classification of Diseases V.10) codes and other conditions and prescriptions.

Patients who had already died or had insufficient information in their medical records were excluded.

\section{Data collection}

The data from the dispensing system of the pharmacy and the medical records constituted a database. Using data from the dispensing system of the pharmacy, we extracted the following patient information collected on first visit: gender, age, marital status, continuous medication use (without interruptions) or intermittent use (non-continuous use, with interruptions; at some point the patient stopped taking 
the drug and then continued to take it), type of antidepressant, and type of benzodiazepine. We also extracted the following information: the presence of comorbidities, clinical indications for an antidepressant, time since diagnosis, use of other drugs and medical specialty of the prescriber. All this information was linked with personal identification numbers in the public health system.

All drugs were classified according to the Anatomical Therapeutic Chemical System, and ICD-10 codes were used to identify the medical diagnoses and comorbidities. We did not include non-prescription medications.

\section{Possible associated factors}

We considered the following variables as risk factors possibly associated with prolonged use of antidepressants and benzodiazepines. For each factor, we previously postulated the direction of the possible effects: (1) age (older vs younger, with a higher risk of prolonged use of benzodiazepines for adults over 35), ${ }^{14}$ (2) gender (women have higher risk than men), ${ }^{24}$ (3) marital status (single vs married, with a higher risk for single individuals; we merged single participants, divorced participants and widows/widowers into the same group), ${ }^{7}$ (4) the time since diagnosis (longer vs shorter, with a higher risk for longer times), ${ }^{1}$ (5) the presence of comorbidities (none vs one or more, with a higher risk for one or more illnesses $),{ }^{10}$ (6) concomitant use of other prescribed drugs (none vs one or more, with a higher risk for those using one or more medications), (7) prescription by physician (psychiatrists vs other, with a higher risk when prescribed by psychiatrists), ${ }^{18}{ }^{24}$ (8) the type of prescription (continuous or intermittent, with a higher risk for intermittent), (9) the type of diagnosis (major depression vs others, including generalised anxiety, pain and bipolar disease, with a higher risk for major depression), ${ }^{10} 16$ and (10) the type of antidepressant (tricyclic vs selective serotonin reuptake inhibitors (SSRIs), with a higher risk for SSRIs; SSRIs cause more agitation, insomnia and anxiety, so it is more common to associate them with benzodiazepines at the beginning of a treatment). ${ }^{25}$

\section{Statistical analysis}

All analyses were performed in STATA V.14.2.

Initially, we obtained the descriptive statistics of the variables studied through frequencies. Later, the variables were stratified based on long-term use of benzodiazepines. We calculated the prevalence ratio (PR) to detect factors associated with the long-term use of benzodiazepines using Poisson regression. We proceeded with a bivariate analysis (unadjusted) as a first step, and as a second step the analysis was adjusted for age, gender, the presence of comorbidities and the type of diagnosis (psychiatric condition). A significance level of $\mathrm{P}<0.05$ and a CI of $95 \%$ were adopted. To certify the reliability of the results, the use of benzodiazepines was recoded into four categories: (1) no use or use for up to 4 weeks, (2) use for 5-12 weeks, (3) use for 13-24 weeks and (4) use for more than 24 weeks. With this variable, we performed a sensitivity analysis using a generalised logistic regression model for ordinal dependent variables. ${ }^{26}$ In this model, we also adjusted for age, gender, the presence of comorbidities and psychiatric conditions, and the results were reported in the form of ORs. To address missing participant data, we did not perform imputation of the data.

\section{RESULTS}

Figure 1 shows the recruitment flow of the research subjects. We identified 1355 users of antidepressants in the public health service of Porto Feliz. Of the total sample, $35.8 \%(\mathrm{n}=485)$ did not meet the inclusion criteria due to death before the study $(0.5 \%, \mathrm{n}=7)$ or incomplete data $(35.3 \%, \mathrm{n}=478)$. A total of 870 people met the inclusion criteria and were included in the analysis. Of the sample analysed, $522(60.0 \%)$ patients were using only antidepressants or were taking antidepressants combined with benzodiazepines for a short period, and 348 (40\%) patients were taking antidepressants combined with benzodiazepines for a prolonged period.

Most of the patients using benzodiazepines for longer periods used antidepressants plus benzodiazepines for more than 24 weeks (71.8\%), and a small number used the two drugs combined for shorter periods: $11.5 \%$ used them for 5-12 weeks and $16.6 \%$ used them for 13-24 weeks.

The study participants are characterised in table 1 . The demographic profile of the sample consisted mainly of middle-aged, married women. Among participants under 20 years of age, no patients used benzodiazepines combined with antidepressants, and among those between 21 and 34 years old, only 47 patients used this combination. Regarding health status, most of the patients had no other chronic diseases but used other drugs.

The studied individuals commonly had 3-5 years since their diagnosis, used intermittent prescriptions, had follow-ups performed by psychiatrists and used SSRI antidepressants.

Most of the patients were using fluoxetine $(52.8 \%)$ or amitriptyline $(15.6 \%)$ as antidepressants. The most prevalent benzodiazepines used in combination with antidepressants were diazepam $(40.9 \%)$ and clonazepam $(33.7 \%)$.

Other antidepressants, such as serotonin-norepinephrine reuptake inhibitors and norepinephrine-dopamine reuptake inhibitors, were not prescribed in the Porto Feliz public health unit. The public pharmacy outlet dispensed only SSRI antidepressants and tricyclic antidepressants.

Table 2 shows the risk factors associated with the prolonged use (more than 4weeks) of an antidepressant plus benzodiazepines in this study. Age above 35 (PR: 2.18, $95 \%$ CI 1.55 to $3.06, \mathrm{P}<0.001$ ), female sex (PR: 1.47 , $95 \% \mathrm{CI} 1.07$ to $2.02, \mathrm{P}=0.019$ ), diagnosis at least 3 years prior (PR: 2.1, 95\% CI 1.6 to $2.8, \mathrm{P}<0.001$ ), use of SSRI antidepressants (PR: 1.7, 95\% CI 1.3 to 2.2, $\mathrm{P}<0.001$ ) and receiving a prescription from a psychiatrist (PR: 6.5, $95 \%$ CI 3.2 to $13.2, \mathrm{P}<0.001$ ) were the factors associated with the long-term use of benzodiazepines, after adjusting for other variables. 


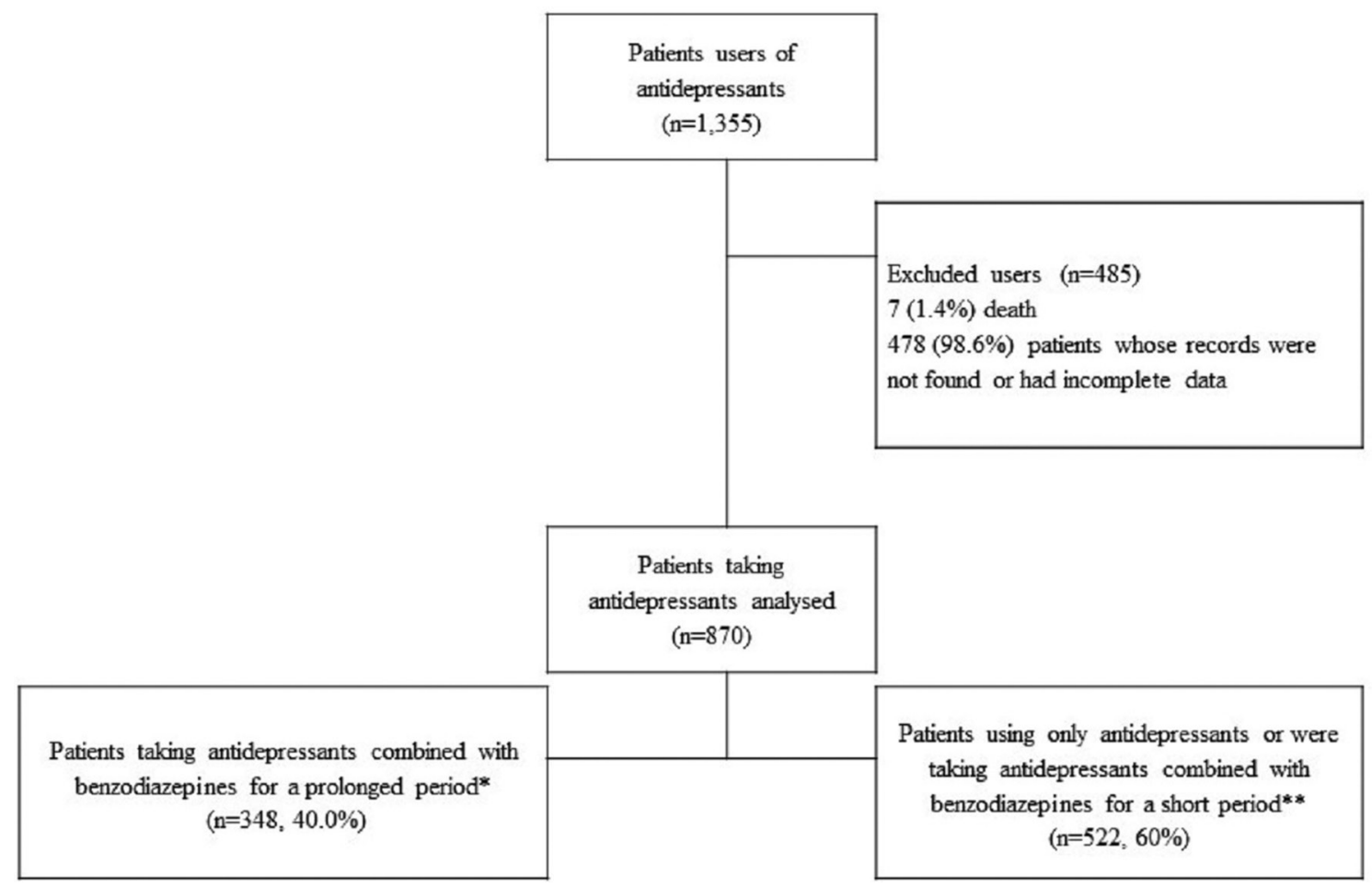

Figure 1 Recruitment flow of the research subjects. *Prolonged period, $>4$ weeks. ${ }^{*}$ Short period, $\leq 4$ weeks.

The sensitivity analysis revealed that being at least 35 years old, female, receiving the diagnosis at least 3 years prior, major depression, use of SSRI antidepressants and receiving a prescription from a psychiatrist act as risk factors (table 3). Having comorbidities and using tricyclic antidepressants exert protective effects. The difference between the sensitivity analysis and the main analysis may be due to the small sample size or poor medical recording.

\section{DISCUSSION}

\section{Main findings}

The present results confirm the high prevalence of longterm use of benzodiazepines (40\%) with antidepressants. Associated risk factors include the following: being female, being 35 years of age or older, being diagnosed over 3 years ago, using SSRI antidepressants rather than tricyclic antidepressants and receiving a prescription from a psychiatrist.

\section{Comparison with prior work and further comments on our findings}

The use of benzodiazepines plus antidepressants has been observed in studies from other countries around the world, including Singapore, ${ }^{14}$ Canada, ${ }^{27}$ the USA, ${ }^{16}$ six European countries (Belgium, France, Germany, Italy, the Netherlands and Spain $)^{1}$ and Brazil. ${ }^{10}$ However, the appropriateness of this prescription has repeatedly been questioned because this therapy often results in the longterm use of benzodiazepines. ${ }^{1728}$

Another study examining use patterns of benzodiazepines and antidepressants in Brazil found that antidepressants and benzodiazepines are highly associated and that patients receiving one of these drugs are 8-11 times more likely to use the other. ${ }^{10}$

Older age was a factor strongly associated with the long-term use of benzodiazepines and antidepressants, a finding consistent with those of other studies, because psychotropic drug consumption tends to increase with age. Possible causes for this increase may include a higher incidence of depressive or anxiety disorders in this age group. ${ }^{21617}$

Female gender was also an important associated factor. Women commonly show higher consumption of psychotropic drugs and greater use of health services than men. ${ }^{24} 29$

The time period of over 3 years since diagnosis was also an associated factor. This time period can be attributed to the chronic and recurrent characteristics of various psychiatric disorders, such as depression and anxiety, or even to the common practice of repeating prescriptions without patient monitoring. Previous studies confirm these findings. ${ }^{1} 3031$ Whenever benzodiazepines are prescribed, regardless of whether it is a new or repeated prescription, it should be remembered that the likelihood of continuing use is considerable.

Once started, benzodiazepines are usually continued beyond the period of their usefulness; that is, the 'standard practice' found does not reflect the best available evidence. ${ }^{75}$ Consulting with a psychiatrist increases the utilisation of these drugs, possibly because psychiatrists typically consult with patients with severe depression. ${ }^{18} 32$

The use of SSRI antidepressants was another important associated factor. One of the possible explanations for 
Table 1 Characteristics of the patients with or without long-term use of benzodiazepine

\begin{tabular}{|c|c|c|c|}
\hline & $\begin{array}{l}\text { Long-term use of } \\
\text { benzodiazepines }\end{array}$ & $\begin{array}{l}\text { No long-term use } \\
\text { of benzodiazepines }\end{array}$ & Tota \\
\hline $\mathrm{N}$ & 348 & 522 & 870 \\
\hline \multicolumn{4}{|l|}{ Age (years) } \\
\hline Up to 34 & $47(13.5)$ & $180(34.5)$ & 227 \\
\hline $35-49$ & $122(35.1)$ & $142(27.2)$ & 264 \\
\hline $50-64$ & $135(38.8)$ & $135(25.8)$ & 270 \\
\hline$\geq 65$ & $44(12.6)$ & 65 (12.5) & 109 \\
\hline Median (IQR) & $50(40-59)$ & $43(29-56)$ & - \\
\hline \multicolumn{4}{|l|}{ Gender } \\
\hline Female & $304(87.4)$ & $398(76.3)$ & 702 \\
\hline Male & $44(12.6)$ & $124(23.7)$ & 168 \\
\hline \multicolumn{4}{|l|}{ Marital status } \\
\hline Married & $202(58.0)$ & $211(40.4)$ & 413 \\
\hline Single ${ }^{*}$ & 102 (29.3) & $174(33.3)$ & 276 \\
\hline \multicolumn{4}{|c|}{ Presence of comorbidities } \\
\hline None & $196(56.3)$ & $277(53.1)$ & 473 \\
\hline One or more & $152(43.7)$ & $245(46.9)$ & 397 \\
\hline \multicolumn{4}{|c|}{ Concomitant use of other drugs } \\
\hline One or more & $175(50.3)$ & $279(53.5)$ & 454 \\
\hline None & $173(49.7)$ & $243(46.5)$ & 416 \\
\hline \multicolumn{4}{|l|}{ Time since diagnosis } \\
\hline Up to 2 years & $89(25.6)$ & $315(60.3)$ & 404 \\
\hline $3-5$ years & $131(37.6)$ & $123(23.6)$ & 254 \\
\hline$\geq 6$ years & $128(36.8)$ & $84(16.1)$ & 212 \\
\hline \multicolumn{4}{|c|}{ Prescription by physician } \\
\hline Psychiatrist & $294(84.5)$ & $211(40.4)$ & 505 \\
\hline Primary care & $46(13.2)$ & $226(43.3)$ & 272 \\
\hline Othert & $8(2.3)$ & 85 (16.3) & 93 \\
\hline \multicolumn{4}{|l|}{ Type of prescription } \\
\hline Intermittent & $179(51.4)$ & $237(45.4)$ & 416 \\
\hline Continuous & $169(48.5)$ & $285(54.6)$ & 454 \\
\hline \multicolumn{4}{|l|}{ Type of diagnosis } \\
\hline Otherł & $77(22.1)$ & $145(27.8)$ & 222 \\
\hline Anxiety & $133(38.2)$ & $186(35.6)$ & 319 \\
\hline Major depression & $138(39.7)$ & $191(36.6)$ & 329 \\
\hline \multicolumn{4}{|l|}{ Type of antidepressant } \\
\hline $\begin{array}{l}\text { Selective serotonin } \\
\text { reuptake inhibitor } \\
\text { antidepressants§}\end{array}$ & $272(78.2)$ & $309(59.2)$ & 581 \\
\hline $\begin{array}{l}\text { Tricyclic } \\
\text { antidepressants }\end{array}$ & $76(21.8)$ & $176(33.7)$ & 252 \\
\hline
\end{tabular}

*Single: individuals who are single, divorced and widows/widowers. †Cardiologist, endocrinologist, neurologist, rheumatologist, pulmonologist and paediatrician.

$\ddagger$ Dissociative disorder, reaction to severe stress and adjustment disorders, mental and behavioural disorders due to use of alcohol, other headache syndromes, and activity and attention disorders. §Fluoxetine, sertraline, paroxetine and citalopram.

ๆAmitriptyline, imipramine, nortriptyline and clomipramine.

this finding is that SSRI antidepressants have been regarded as first-line treatments for major depression and anxiety ${ }^{33}$ and commonly have adverse effects such as agitation and sleep disorders in early treatment. ${ }^{34}$ Therefore, the strategy of adding benzodiazepines in early treatment can reduce the anxiety and insomnia often experienced during the latency period of the antidepressant. Therapy with antidepressants plus benzodiazepines (for up to 4 weeks) can lead to greater compliance, partial suppression of the adverse effects and possibly a reduction in the risk of suicide during early treatment. ${ }^{25}$

On the other hand, tricyclic antidepressants are often prescribed for other indications beyond depression, including migraines, chronic pain and sleep, so patients receiving tricyclic antidepressants may not need another sleep aid. ${ }^{35}$ There could likely be other confounding factors, and this finding should be interpreted cautiously.

We considered the cut-point of 4 weeks a decisive indicator of inappropriate use, because there is no evidence of the effectiveness of benzodiazepines in the long term, and all international guidelines recommend them for short-term use. ${ }^{71536-38}$ Benzodiazepines are recommended especially as emergency treatment for mood symptoms, immediately relieving symptoms such as insomnia, agitation, anxiety and suicidal impulses. When there is a potential risk of developing dependence, antipsychotics (quetiapine, fluphenazine or risperidone) may be more appropriate. ${ }^{39}$ Furthermore, when long-term treatments for the diagnosis of affective disorders are needed, the guidelines recommend prescribing SSRI antidepressants and not benzodiazepines. ${ }^{37}$

Knowledge of translated guidelines regarding recommended strategies for benzodiazepine discontinuation could contribute to clinician and patient education and decrease the overuse of benzodiazepines. The following strategies can also produce better outcomes ${ }^{38}$ : a combination of the gradual tapering of doses, a letter from a clinician recommending discontinuation and explaining the risks of long-term benzodiazepine use, self-help instructions, and patient education about the advantages of discontinuation or psychotherapy.

The fact that prescriptions are generated without the need for a consultation is a truth universally acknowledged but not justified by any recent evidence, and the proportion of the population on repeatedly prescribed medication is high and increasing, which has implications, risks and costs. ${ }^{39}$ These factors may be related to the data on the large and widespread suboptimal use of benzodiazepines observed in Brazil, suggesting chronic and potential overuse of the drugs. ${ }^{10}$ Further research is needed to deepen our understanding of the clinical or service delivery-related problems that underlie prolonged use.

\section{Strengths and limitations of the study}

This study represents the first detailed report on the long-term use of benzodiazepines with antidepressants in Brazilian patients from the public health services of Porto 
Table 2 Risk factors associated with the long-term use (more than 4 weeks) of antidepressants and benzodiazepines

\begin{tabular}{|c|c|c|c|c|}
\hline & PR, 95\% Cl unadjusted & $P$ value & PR, $95 \% \mathrm{Cl}$ adjusted ${ }^{*}$ & $P$ value \\
\hline \multicolumn{5}{|l|}{ Age (years) } \\
\hline Up to 34 & 1.00 & - & 1.00 & - \\
\hline $35-49$ & 2.23 (1.59 to 3.12$)$ & $<0.001$ & 2.18 (1.55 to 3.06$)$ & $<0.001$ \\
\hline $50-64$ & 2.41 (1.73 to 3.37$)$ & $<0.001$ & 2.42 (1.72 to 3.39$)$ & $<0.001$ \\
\hline$\geq 65$ & 1.95 (1.29 to 2.94$)$ & 0.001 & 1.99 (1.31 to 3.02$)$ & 0.001 \\
\hline \multicolumn{5}{|l|}{ Gender } \\
\hline Male & 1.00 & - & 1.00 & - \\
\hline Female & 1.65 (1.21 to 2.27$)$ & 0.002 & 1.47 (1.07 to 2.02$)$ & 0.019 \\
\hline \multicolumn{5}{|l|}{ Marital status } \\
\hline Single & 1.00 & - & 1.00 & - \\
\hline Married & 0.76 (0.60 to 0.96$)$ & 0.022 & 0.88 (0.69 to 1.13$)$ & 0.323 \\
\hline \multicolumn{5}{|l|}{ Presence of comorbidities } \\
\hline None & 1.00 & - & 1.00 & - \\
\hline One or more & $0.92(0.75$ to 1.14$)$ & 0.464 & 0.83 (0.67 to 1.04$)$ & 0.104 \\
\hline \multicolumn{5}{|l|}{ Concomitant use of other drugs } \\
\hline None & 1.00 & - & 1.00 & - \\
\hline One or more & $0.93(0.75$ to 1.14$)$ & 0.479 & 0.93 (0.71 to 1.22$)$ & 0.597 \\
\hline \multicolumn{5}{|l|}{ Time since diagnosis } \\
\hline Up to 2 years & 1.00 & - & 1.00 & - \\
\hline $3-5$ years & 2.34 (1.79 to 3.06$)$ & $<0.001$ & 2.15 (1.63 to 2.83$)$ & $<0.001$ \\
\hline$\geq 6$ years & 2.74 (2.09 to 3.59$)$ & $<0.001$ & 2.48 (1.87 to 3.29$)$ & $<0.001$ \\
\hline \multicolumn{5}{|l|}{ Prescription by physician } \\
\hline Other & 1.00 & - & 1.00 & - \\
\hline Primary care & 1.97 (0.93 to 4.17$)$ & 0.078 & 1.88 (0.87 to 4.02$)$ & 0.106 \\
\hline Psychiatrist & 6.77 (3.35 to 13.66$)$ & $<0.001$ & 6.51 (3.20 to 13.22) & $<0.001$ \\
\hline \multicolumn{5}{|l|}{ Type of prescription } \\
\hline Intermittent & 1.00 & - & 1.00 & - \\
\hline Continuous & 0.87 (0.70 to 1.07$)$ & 0.177 & 0.95 (0.76 to 1.19$)$ & 0.682 \\
\hline \multicolumn{5}{|l|}{ Type of diagnosis } \\
\hline Other & 1.00 & - & 1.00 & - \\
\hline Major depression & $1.20(0.91$ to 1.59$)$ & 0.199 & 1.27 (0.96 to 1.69$)$ & 0.098 \\
\hline Anxiety & 1.21 (0.92 to 1.60$)$ & 0.181 & $1.21(0.91$ to 1.61$)$ & 0.182 \\
\hline \multicolumn{5}{|l|}{ Type of antidepressant } \\
\hline Tricyclic antidepressants & 0.69 (0.53 to 0.88$)$ & 0.004 & 0.75 (0.57 to 0.99$)$ & 0.039 \\
\hline $\begin{array}{l}\text { Selective serotonin reuptake } \\
\text { inhibitor antidepressants }\end{array}$ & 1.78 (1.38 to 2.30$)$ & $<0.001$ & $1.70(1.30$ to 2.23$)$ & $<0.001$ \\
\hline
\end{tabular}

*Adjusted for age, sex, type of diagnosis and presence of comorbidities.

PR, prevalence ratio.

Feliz. We obtained pharmacy records of medication use and information from medical records and proceeded to crosscheck information to ensure accuracy.

There are four limitations to our study. First, although the study follows all the recommendations for observational studies considered in the Strengthening the Reporting of Observational Studies in Epidemiology statement, there is the possibility of confounding factors that have not been considered.
The cross-sectional design of this study may allow us to observe an association without determining its direction over time. We reported the prevalence values and associated risk factors for the prolonged use of benzodiazepines, but it was not possible to establish causal relationships between these factors and prolonged use of benzodiazepines. Second, our study may not be large enough to obtain narrow CIs, which may overestimate or underestimate the PRs. A post hoc power analysis 
Table 3 Results stratified by degree of exposure and the sensitivity analysis obtained by ordinal regression

\begin{tabular}{|c|c|c|c|c|c|}
\hline & 5-12 weeks & 13-24 weeks & $\geq 25$ weeks & OR, 95\% Cl, adjusted* & $P$ value \\
\hline \multicolumn{6}{|l|}{ Age (years) } \\
\hline Up to 34 & 12 & 16 & 19 & 1.00 & - \\
\hline $50-64$ & 5 & 16 & 114 & 4.71 (3.13 to 7.08$)$ & $<0.001$ \\
\hline$\geq 65$ & 4 & 4 & 36 & 3.17 (1.91 to 5.27$)$ & $<0.001$ \\
\hline Male & 8 & 5 & 31 & 1.00 & - \\
\hline Female & 32 & 52 & 220 & 1.81 (1.24 to 2.66$)$ & 0.002 \\
\hline \multicolumn{6}{|l|}{ Marital status } \\
\hline Single & 15 & 35 & 151 & 1.00 & - \\
\hline Married & 14 & 16 & 72 & 0.74 (0.52 to 1.04$)$ & 0.082 \\
\hline One or more & 14 & 29 & 109 & 0.71 (0.53 to 0.94$)$ & 0.018 \\
\hline \multicolumn{6}{|l|}{ Concomitant use of other drugs } \\
\hline None & 26 & 26 & 121 & 1.00 & - \\
\hline One or more & 14 & 31 & 130 & $0.92(0.65$ to 1.31$)$ & 0.652 \\
\hline \multicolumn{6}{|l|}{ Time since diagnosis } \\
\hline Up to 2 years & 16 & 15 & 58 & 1.00 & - \\
\hline 3-5years & 10 & 16 & 105 & 3.82 (2.69 to 5.42 ) & $<0.001$ \\
\hline$\geq 6$ years & 14 & 26 & 88 & 4.42 (3.05 to 6.41$)$ & $<0.001$ \\
\hline \multicolumn{6}{|l|}{ Prescription by physician } \\
\hline \multicolumn{6}{|l|}{ Type of diagnosis } \\
\hline Other & 7 & 14 & 56 & 1.00 & - \\
\hline Major depression & 15 & 21 & 97 & 1.48 (1.03 to 2.13$)$ & 0.034 \\
\hline Anxiety & 18 & 22 & 98 & 1.39 (0.97 to 2.00$)$ & 0.073 \\
\hline \multicolumn{6}{|l|}{ Type of antidepressant } \\
\hline Tricyclic antidepressants & 10 & 15 & 51 & $0.60(0.43$ to 0.84$)$ & 0.003 \\
\hline $\begin{array}{l}\text { Selective serotonin reuptake } \\
\text { inhibitor antidepressants }\end{array}$ & 30 & 42 & 200 & 2.48 (1.78 to 3.47$)$ & $<0.001$ \\
\hline
\end{tabular}

${ }^{\star}$ Adjusted for age, sex, type of diagnosis and presence of comorbidities.

suggests that our sample may detect only differences above $10 \%$ with $80 \%$ of precision. Third, we can only deduce adherence from pharmacy records, that is, we do not know whether patients took doses as instructed. Thus, our findings relate to the antidepressants and benzodiazepines prescribed and obtained from the pharmacy, which may not correspond to actual use. Fourth, this study included a non-probabilistic sample from Porto Feliz; however, it refers to a context with a strong presence in the public health services, where all records were collected.

The public health system of Brazil assists $75 \%$ of the population in the cities. Furthermore, in Brazil, there is no information system that allows the collection of prescription data and medical records from the whole country. For this reason, researchers examine regional/ local data to capture the behaviour of users and prescribers. Thus, it is likely that the findings identified 
in Porto Feliz are similar to those in other cities. In addition, the patterns of benzodiazepine use found in this study do not differ from those of other countries.

\section{CONCLUSION}

This study represents the first detailed report of the prolonged use of benzodiazepines with antidepressants in Brazilian patients from the public health system.

We found evidence of long-term use of benzodiazepines in patients receiving antidepressants and identified additional associated risk factors, including being female, being 35 years of age or older, having a longer duration of illness, using SSRI antidepressants and receiving a prescription from a psychiatrist.

We believe that the prescription patterns for these drugs should be reviewed, because our findings show that clinical practices can be improved to encourage more rational use of the available drugs.

Acknowledgements The authors are grateful to the Department of Pharmaceutical Assistance of the Health Municipal Secretary in Porto Feliz for the support, cooperation and help in providing data from the database and other relevant information from their files.

Contributors LCL, IF had the original idea and developed the study protocol. IF, LCL, MTS performed data analysis and drafted the manuscript. IF, LCL, MTS contributed to data collection. All authors contributed to the preparation of the manuscript and read and approved the final version.

Funding This research received no specific grant from any funding agency in the public, commercial or not-for-profit sectors.

Competing interests None declared.

Patient consent Not required.

Ethics approval This study was approved by the Municipal Health Secretary of Porto Feliz, State of São Paulo, Brazil, and by the Ethics Committee for Clinical Research of the University of Sorocaba on 13 April 2010, with protocol number $003 / 2010$.

Provenance and peer review Not commissioned; externally peer reviewed.

Data sharing statement No database available.

Open Access This is an Open Access article distributed in accordance with the Creative Commons Attribution Non Commercial (CC BY-NC 4.0) license, which permits others to distribute, remix, adapt, build upon this work non-commercially, and license their derivative works on different terms, provided the original work is properly cited and the use is non-commercial. See: http://creativecommons.org/ licenses/by-nc/4.0/

(C) Article author(s) (or their employer(s) unless otherwise stated in the text of the article) 2018. All rights reserved. No commercial use is permitted unless otherwise expressly granted.

\section{REFERENCES}

1. Demyttenaere K, Bonnewyn A, Bruffaerts R, et al. Clinical factors influencing the prescription of antidepressants and benzodiazepines: results from the European study of the epidemiology of mental disorders (ESEMeD). J Affect Disord 2008;110:84-93.

2. Fleck MP, Berlim MT, Lafer B, et al. [Review of the guidelines of the Brazilian Medical Association for the treatment of depression (Complete version)]. Rev Bras Psiquiatr 2009;31(Suppl 1):S7-17.

3. Schmidt MI, Duncan BB. Azevedo e Silva G, Menezes AM, Monteiro CA, Barreto SM, Chor D, Menezes PR. Chronic non-communicable diseases in Brazil: burden and current challenges. Lancet 2011;377:1949-61.

4. Lima MC, Menezes PR, Carandina L, et al. [Common mental disorders and the use of psychoactive drugs: the impact of socioeconomic conditions]. Rev Saude Publica 2008;42:717-23.
5. Kessler RC, Birnbaum HG, Shahly V, et al. Age differences in the prevalence and co-morbidity of DSM-IV major depressive episodes: results from the WHO World Mental Health Survey Initiative. Depress Anxiety 2010;27:351-64.

6. Gardarsdottir H, Heerdink ER, van Dijk L, et al. Indications for antidepressant drug prescribing in general practice in the Netherlands. J Affect Disord 2007;98:109-15.

7. Manthey L, van Veen T, Giltay EJ, et al. Correlates of (inappropriate) benzodiazepine use: the Netherlands Study of Depression and Anxiety (NESDA). Br J Clin Pharmacol 2011;71:263-72.

8. Opaleye ES, Ferri CP, Locatelli DP, et al. Nonprescribed use of tranquilizers and use of other drugs among Brazilian students. Rev Bras Psiquiatr 2014;36:16-23.

9. Mugunthan K, McGuire T, Glasziou P. Minimal interventions to decrease long-term use of benzodiazepines in primary care: a systematic review and meta-analysis. Br J Gen Pract 2011;61:573-8

10. Brunoni AR, Nunes MA, Figueiredo R, et al. Patterns of benzodiazepine and antidepressant use among middle-aged adults. the Brazilian longitudinal study of adult health (ELSA-Brasil). J Affect Disord 2013;151:71-7.

11. Billioti de Gage S, Bégaud B, Bazin F, et al. Benzodiazepine use and risk of dementia: prospective population based study. $B M J$ 2012;345:e6231.

12. Pariente A, Dartigues JF, Benichou J, et al. Benzodiazepines and injurious falls in community dwelling elders. Drugs Aging 2008;25:61-70.

13. Ballokova A, Peel NM, Fialova D, et al. Use of benzodiazepines and association with falls in older people admitted to hospital: a prospective cohort study. Drugs Aging 2014;31:299-310.

14. Subramaniam M, He VY, Vaingankar JA, et al. Prevalence of and factors related to the use of antidepressants and benzodiazepines: results from the Singapore Mental Health Study. BMC Psychiatry 2013;13:231.

15. Furukawa TA, Streiner DL, Young LT. Antidepressant and benzodiazepine for major depression. The Cochrane database of systematic reviews 2002;1:CD001026.

16. Valenstein M, Taylor KK, Austin K, et al. Benzodiazepine use among depressed patients treated in mental health settings. Am J Psychiatry 2004;161:654-61.

17. Vedia Urgell C, Bonet Monne S, Forcada Vega C, et al. Estudio de utilización de psicofármacos en atención primaria. Atención Primaria 2005;36:239-45.

18. Sanyal C, Asbridge M, Kisely S, et al. The Utilization of Antidepressants and Benzodiazepines among People with Major Depression in Canada. The Canadian Journal of Psychiatry 2011;56:667-76

19. Campos Junior A, Amarante PDdeC, PDdC A. Estudo sobre práticas de cuidado em saúde mental na Atenção Primária: o caso de um município do interior do estado do Rio de Janeiro. Cad Saude Colet 2015;23:425-35.

20. Brett J, Murnion B. Management of benzodiazepine misuse and dependence. Aust Prescr 2015;38:152-5.

21. Brazil. Brazilian Institute of Statistics and Geography. Population http://www.ibge.gov.br/home/mapa_site/mapa_site.php\#populacao (accessed 10 Dec 2015)

22. BMJ Best Practice. Generalized Anxiety Disorder. http://brasil. bestpractice.bmj.com/bestpractice/monograph/120/treatment/ details.html (accessed 10 Dec 2015).

23. BMJ Best Practice. Depression in adults. http://brasil.bestpractice. bmj.com/best-practice/monograph/55/treatment/step-by-step.html (accessed 10 Dec 2015)

24. Quintana MI, Andreoli SB, Peluffo MP, et al. Psychotropic Drug Use in São Paulo, Brazil--An Epidemiological Survey. PLoS One 2015;10:e0135059.

25. Smith WT, Londborg PD, Glaudin V, et al. Short-term augmentation of fluoxetine with clonazepam in the treatment of depression: a doubleblind study. Am J Psychiatry 1998;155:1339-45.

26. Ananth CV, Kleinbaum DG. Regression models for ordinal responses: a review of methods and applications. Int J Epidemio 1997;26:1323-33.

27. Sanyal C, Asbridge M, Kisely S, et al. The utilization of antidepressants and benzodiazepines among people with major depression in Canada. Can J Psychiatry 2011;56:667-76.

28. Stafford RS, Ausiello JC, Misra B, et al. National patterns of depression treatment in primary care. The Primary Care Companion to The Journal of Clinical Psychiatry 2000;02:211-6.

29. Garcias CMM, Pinheiro RT, Garcias GdeL, et al. Prevalência e fatores associados ao uso de antidepressivos em adultos de área urbana de Pelotas, Rio Grande do Sul, Brasil, em 2006. Cad Saude Publica 2008;24:1565-71. 
30. Neutel Cl, Walop W, Patten SB. Can continuing benzodiazepine use be predicted? Can J Clin Pharmacol 2003;10:202-6.

31. Neutel Cl. The epidemiology of long-term benzodiazepine use. Int Rev Psychiatry 2005;17:189-97.

32. Blay SL, Fillenbaum GG, Pitta JC, et al. Factors associated with antidepressant, anxiolytic, and other psychotropic medication use to treat psychiatric symptoms in the city of São Paulo, Brazil. Int Clin Psychopharmacol 2014;29:157-65.

33. Lam RW, Kennedy SH, Grigoriadis S, et al. Canadian Network for Mood and Anxiety Treatments (CANMAT) clinical guidelines for the management of major depressive disorder in adults. III. Pharmacotherapy. J Affect Disord 2009;117(Suppl 1):S26-S43.

34. Furukawa TA, Streiner DL, Young LT. Is antidepressantbenzodiazepine combination therapy clinically more useful? A metaanalytic study. J Affect Disord 2001;65:173-7.

35. Wong J, Motulsky A, Abrahamowicz M, et al. Off-label indications for antidepressants in primary care: descriptive study of prescriptions from an indication based electronic prescribing system. $B M J$ 2017;356:j603.

36. Ravindran AV, Lam RW, Filteau MJ, et al. Canadian Network for Mood and Anxiety Treatments (CANMAT) Clinical guidelines for the management of major depressive disorder in adults. V. Complementary and alternative medicine treatments. J Affect Disord 2009;117(Suppl 1):S54-64.

37. Pélissolo A, Maniere F, Boutges B, et al. [Anxiety and depressive disorders in 4,425 long term benzodiazepine users in general practice]. Encephale 2007;33:32-8.

38. Discontinuation strategies for patients with long-term benzodiazepine use: a review of clinical evidence and guidelines [Internet]. Ottawa (ON): Canadian Agency for Drugs and Technologies in Health, 2015. http://www.ncbi.nlm.nih.gov/books/NBK310990/ (accessed 10 Oct 2015)

39. Petty DR, Zermansky AG, Alldred DP. The scale of repeat prescribing-time for an update. BMC Health Serv Res 2014;14:76. 